Check for updates

Cite this: RSC Adv., 2017, 7, 29909

Received 30th March 2017

Accepted 25th May 2017

DOI: $10.1039 / \mathrm{c} 7 \mathrm{ra03659k}$

rsc.li/rsc-advances

\section{Porous $\mathrm{SnO}_{2}$ hexagonal prism-attached Pd/rGO with enhanced electrocatalytic activity for methanol oxidation}

\begin{abstract}
Yiran Hu, Tao Mei, Jinhua Li, (D) Jianying Wang and Xianbao Wang (D) *
Porous $\mathrm{SnO}_{2}$ hexagonal prisms, as a new promoter, were attached to Pd-based systems held by a reduced graphene oxide $(\mathrm{rGO})$ support $\left(\mathrm{Pd}-\mathrm{SnO}_{2} / \mathrm{rGO}\right)$ for the catalysis of the electrooxidation reaction of methanol. Cyclic voltammetry (CV) tests revealed that the electrocatalytic activity and stability were substantially improved by $\mathrm{SnO}_{2}$ with a special morphology. The specific activity ( $\mathrm{SA}, j_{\mathrm{k}}$, area) and mass activity (MA, $j_{\mathrm{k}}$, area) of $\mathrm{Pd}-\mathrm{SnO}_{2} / \mathrm{rGO}$ were enhanced 1.31 and 3.3 times those of the $\mathrm{Pd} / \mathrm{rGO}$ catalyst, respectively. Moreover, the $\mathrm{CO}$-tolerance was also remarkably enhanced due to the presence of $\mathrm{SnO}_{2}$. It is believed that higher surface areas, more active sites, which are offered by the porous architecture of $\mathrm{SnO}_{2}$, as well as the synergetic effect between all components contribute to the improvement of the catalytic activities of the $\mathrm{Pd}-\mathrm{SnO}_{2} / \mathrm{rGO}$ catalysts. Cost savings and the $\mathrm{CO}$-poisoning obstacle being surmounted, which are the two main probing directions for elevating the overall performance of direct methanol fuel cells, makes the as-prepared $\mathrm{Pd}-\mathrm{SnO}_{2} / \mathrm{rGO}$ a promising electrocatalyst.
\end{abstract}

\section{Introduction}

Direct methanol fuel cells (DMFCs) possess significant potential for portable devices and transportation utilization since the possibility of directly using fuel (methanol) at low operating temperatures and the interoperability of the existing distribution and consumption pattern of liquid fuel. ${ }^{\mathbf{1 - 4}}$ For methanol electrooxidation at the anode, palladium is regarded as an eyecatching alternative to platinum as a catalyst. Besides their lower price as compared to the Pt-based electrocatalysts, Pdbased electrocatalysts can achieve appreciable activity for the oxidation of methanol in a high $\mathrm{pH}$ environment, where nonprecious metals are adequately stable for electrochemical applications. ${ }^{5}$ The stability of base metals in an alkaline environment provides us more choices to cut down the expenditure of the catalysts. In addition, the better CO-type intermediates tolerance was shown in Pd-based electrocatalysts than in Ptbased electrocatalysts, especially when the $\mathrm{pH}$ is high. ${ }^{6}$ The intermediates during the electrooxidation of methanol, especially carbon monoxide, are strongly absorbed onto the active site of pure noble metals, such as Pd, and limit the catalytic efficiency.

To save costs as well as overcome the CO-poisoning obstacle, a number of studies have been performed to achieve

Hubei Collaborative Innovation Center for Advanced Organic Chemical Materials, Key Laboratory for the Green Preparation and Application of Functional Materials, Ministry of Education, Hubei Key Laboratory of Polymer Materials, School of Materials Science and Engineering, Hubei University, Wuhan 430062, China. E-mail: wangxb68@aliyun.com; Fax: +86 2788661729; Tel: +86 2788661729 a satisfactory effectiveness of the Pd-based electrocatalysts. The most widely accepted strategy is to use less-precious metals to combine alloys, such as $\mathrm{Pd}-\mathrm{Cu},{ }^{7,8} \mathrm{Pd}-\mathrm{Ni},{ }^{9}$ and $\mathrm{Pd}-\mathrm{Ag},{ }^{10,11}$ or introduce metal oxides, such as $\mathrm{NiO},{ }^{12} \mathrm{CeO}_{2}$ (ref. 13), $\mathrm{MnO}_{2}$ (ref. 13) and $\mathrm{SnO}_{2}$ (ref. 13), as co-catalysts. Compared to pure metals, metal oxides provide more possibilities of forming a construction that is more complicated and stable. Among all types of metal oxide promoters, $\mathrm{SnO}_{2}$ attracts significant attention due to its great stability as well as particular electrochemical properties. It has been extensively used in protection against corrosion, catalysts, and even been considered as a substitute for commercial graphite as an anode of a lithium-ion battery (LIB). ${ }^{\mathbf{1 1 4}}$ Moreover, $\mathrm{SnO}_{2}$ can be a promoter of water displacement, which is the step that determines the rate of methanol oxidation. ${ }^{15}$

Furthermore, a proper support should be selected for the reason that the inevitable aggregation of nanosized catalysts may reduce the activity of the materials. The large surface areas and numerous active sites of the nanoparticles are crucial to the catalytic characteristics, on account of the surface where the catalytic reaction usually proceeds. Among the carbon materials, graphene is appropriate for Pd particles to disperse on it. Its ultrahigh electrical conductivity, large surface area, and abundant functional groups (hydroxyls, epoxides, carbonyls, etc.), which can immobilize and fix nanoparticles, can theoretically enhance the properties of the Pd-based electrocatalysts. ${ }^{16-19}$

Apart from the characteristics of each component, some outstanding superior and synergetic properties can be manifested when they are smartly integrated together. For instance, the electronic configuration, stability, and flexibility of the 
structures and the efficiency of electron transfer might be enhanced, as well as the number of electroactive sites can be increased. ${ }^{20-22}$

Herein, porous $\mathrm{SnO}_{2}$ hexagonal prism-attached $\mathrm{Pd} / \mathrm{rGO}$ was prepared by the co-reduction of $\mathrm{PdCl}_{4}{ }^{2-}$ and GO with porous $\mathrm{SnO}_{2}$ hexagonal prisms, which was pre-prepared with water soluble chitosan as a dispersing agent in deionized pure water and excess $\mathrm{NaBH}_{4}$ as a reductant. The oil-bath reaction under constant pressure and relatively low temperature conserves energy and is more practicable for large-scale production. Although $\mathrm{SnO}_{2}$-enhanced Pd-based electrocatalysts with carbon supports have been reported, to the best of our knowledge, $\mathrm{SnO}_{2}$ with a specific morphology has never been used in anodic catalysts for methanol oxidation. The porous $\mathrm{SnO}_{2}$ hexagonal prism obtained in advance was not destroyed during the entire reduction reaction and provided more active sites. Highperformance catalysts always have high surface areas and some of them have a porous construction. The interior hollow parts of the porous $\mathrm{SnO}_{2}$ decrease the quantity of the buried nonfunctional Pd atoms, and the uncommon geometry offers a great possibility to trim physical and chemical properties. ${ }^{23}$ Compared to pure Pd supported on rGO or on porous $\mathrm{SnO}_{2}$ hexagon, the as-prepared porous $\mathrm{SnO}_{2}$ hexagonal prismattached Pd/rGO exhibits superior activity towards the oxidation of methanol that benefits from higher surface areas, more active sites, which were offered by the individual components, as well as the synergetic effect between all of them.

\section{Experimental}

\subsection{Chemicals}

Every reagent was maintained as received and no further purification was carried out before use. Analytical grade $\mathrm{SnCl}_{4}$ $\cdot 5 \mathrm{H}_{2} \mathrm{O}, \mathrm{NaOH}, \mathrm{CuCl}_{2} \cdot \mathrm{H}_{2} \mathrm{O}, \mathrm{NaBH}_{4}, \mathrm{PdCl}_{2}$, and $\mathrm{CH}_{3} \mathrm{OH}$ were obtained from Sinopharm Chemical Reagent Co. Water soluble chitosan was bought from Zhejiang Aoxing Biotechnology Co. Ltd. The few-layered GO was purchased from Hunan Fenghua Chemical Co. The experimental deionized water was freshly processed by a P60-CY Kertone Ultrapure Water System (Kertone Water Treatment Co. Ltd, resistivity $=18.25 \mathrm{M} \Omega \mathrm{cm}$ ).

\subsection{Synthesis of the porous $\mathrm{SnO}_{2}$ hexagonal prisms}

The porous $\mathrm{SnO}_{2}$ hexagonal prisms were synthesized using a water-bath method with some modification. ${ }^{24}$ In a typical synthesis of the porous $\mathrm{SnO}_{2}$ hexagonal prisms, first $0.79 \mathrm{~g}$ of $\mathrm{SnCl}_{4} \cdot 5 \mathrm{H}_{2} \mathrm{O}$ was dissolved in $100 \mathrm{~mL}$ of distilled water under stirring at room temperature, and then, $0.76 \mathrm{~g}$ of $\mathrm{NaOH}$ was added under continuous vigorous stirring. After the solution became clear, $50 \mathrm{~mL}$ solution of $0.375 \mathrm{~g} \mathrm{CuCl} 2 \cdot \mathrm{H}_{2} \mathrm{O}$ was poured into the abovementioned uniform solution at $30{ }^{\circ} \mathrm{C}$ and was stirred for $15 \mathrm{~min}$, resulting in a milky blue sediment. The resultant blend was allowed to stand at $30{ }^{\circ} \mathrm{C}$ for $6 \mathrm{~h}$. The obtained sediment was centrifuged, ultrasonically cleaned using ultrapure water and absolute ethyl alcohol three times each and kept in a drying oven at $50{ }^{\circ} \mathrm{C}$ for $12 \mathrm{~h}$. Subsequently, the product was annealed at $620{ }^{\circ} \mathrm{C}$ for $2 \mathrm{~h}$ in air atmosphere, resulting in a black powder. The black powder was soaked in 50 $\mathrm{mL}$ of $3.0 \mathrm{M} \mathrm{HCl}$ for $30 \mathrm{~min}$ at room temperature under stirring until the powder totally turned off-white. Finally, the off-white powder was washed with ultrapure water until the $\mathrm{pH}$ of the upper clear water was neutral.

\subsection{Preparation of the porous $\mathrm{SnO}_{2}$ hexagonal prism- attached Pd/rGO}

Porous $\mathrm{SnO}_{2}$ hexagonal prism-attached Pd/rGO catalyst (denoted as $\mathrm{SnO}_{2}-\mathrm{Pd} / \mathrm{rGO}$ ) was obtained via a reduction method in only one step. In the standard preparation, $60 \mathrm{mg}$ of GO powder was first ultrasonically dispersed in $50 \mathrm{~mL}$ of distilled water for $1 \mathrm{~h}$. The mixture was obtained by blending $10 \mathrm{mg}$ of the porous $\mathrm{SnO}_{2}$ hexagonal prisms and was homogenously dispersed in 20 $\mathrm{mL}$ water after ultrasonication for $10 \mathrm{~min}, 20 \mathrm{~mL} \mathrm{PdCl}_{2}$ solution (5 mM), $2 \mathrm{~mL}$ solution of water soluble chitosan (0.1\%) together with the obtained GO homogeneous solution. The abovementioned mixture was transferred into a $150 \mathrm{~mL}$ roundbottomed flask and constantly stirred for $30 \mathrm{~min}$. After this, the uniform solution was placed in an oil bath. When the temperature reached $100{ }^{\circ} \mathrm{C}$, a $20 \mathrm{~mL}$ solution containing $1.2 \mathrm{~g}$ $\mathrm{NaBH}_{4}$ was added dropwise into the flask under continuous stirring. The oil bath was controlled at $100{ }^{\circ} \mathrm{C}$ for $4 \mathrm{~h}$ to obtain the $\mathrm{SnO}_{2}-\mathrm{Pd} / \mathrm{rGO}$ catalyst.

\subsection{Material characterization}

The morphology and microstructure of the catalyst were observed using transmission electron microscopy (TEM, Tecnai F20) and field emission scanning electron microscopy (FE-SEM, JSM7100F). Energy dispersive X-ray spectroscopy (EDX) was used to analyze the mass distribution of the elements using an analyzer attached to the FE-SEM. Powder XRD was carried out using a D8-Advance diffractometer (Bruker, Germany) with a Cu $\mathrm{K} \alpha$ radiation source $(\lambda=0.15418 \mathrm{~nm})$. The surface elemental composition of the sample was investigated via X-ray photoelectron spectroscopy (XPS; Thermo Fisher Scientific Escalab 250Xi).

\subsection{Electrochemical measurements}

A CHI760E electrochemical workstation (Shanghai Chenhua, China) was employed for the electrochemical studies at room temperature $\left(\sim 25{ }^{\circ} \mathrm{C}\right)$. The measurements were performed using a three-electrode configuration that was composed of a modified glass carbon electrode (GCE) (3 $\mathrm{mm}$ in diameter), a platinum electrode, and a saturated calomel electrode (SCE) as the working, counter, and reference electrodes, respectively. Before the surface coating, the GCE was polished to a mirrorlike finish with 0.3 and $0.05 \mu \mathrm{m}$ alumina powder and rinsed with nitric acid solution, ethanol, and doubly distilled water using an ultrasonic cleaner and dried in air. Each specimen was ultrasonically dispersed in $500 \mu \mathrm{L}$ of ethanol to obtain a uniform catalyst ink of $2 \mathrm{mg} \mathrm{mL}{ }^{-1}$. After at least $60 \mathrm{~min}$ of ultrasonic cleaning, a $3 \mu \mathrm{L}$ droplet of the resulting mixture was pressed onto the polished GCE and dried at $25{ }^{\circ} \mathrm{C}$ for $1 \mathrm{~h}$. High purity $\mathrm{N}_{2}$ was utilized to deaerate the electrolyte for at least $30 \mathrm{~min}$ before all the measurements. For the methanol 
electrooxidation tests, an alkaline solution with $0.5 \mathrm{M} \mathrm{KOH}$ and $1 \mathrm{M} \mathrm{CH}_{3} \mathrm{OH}$ was used as the electrolyte.

\section{Results and discussion}

The porous $\mathrm{SnO}_{2}$ hexagonal prism was prepared using a special method without any template. The solid hexagonal prisms of copper tin hydroxide were first obtained through the reaction of $\mathrm{SnCl}_{4} \cdot 5 \mathrm{H}_{2} \mathrm{O}$ and $\mathrm{CuCl}_{2} \cdot \mathrm{H}_{2} \mathrm{O}$ with $\mathrm{NaOH}$ via a water-bath method. After the basic morphology was successfully attained with the help of $\mathrm{CuCl}_{2} \cdot \mathrm{H}_{2} \mathrm{O}$, the hydroxide was separated into $\mathrm{CuO}$ and $\mathrm{SnO}_{2}$ after the annealing process with the morphology being retained. Taking the stability of $\mathrm{SnO}_{2}$ under an acidic condition into consideration, $3 \mathrm{M} \mathrm{HCl}$ was used to remove the $\mathrm{CuO}$ part and the porous nanostructures of $\mathrm{SnO}_{2}$ were obtained from the remaining vacancies of $\mathrm{CuO}$. The oil bath with $\mathrm{NaBH}_{4}$ as a reducing agent provides an alkaline environment, which is appropriate for GO reduction. Water-soluble chitosan as a dispersing agent prevents the rGO assembling to graphite to a great extent. The formation strategy for preparing $\mathrm{Pd}-\mathrm{SnO}_{2} /$ rGO is demonstrated in scheme 1.

The porous $\mathrm{SnO}_{2}$ hexagonal prism was synthesized with a length of $0.4-1.0 \mu \mathrm{m}$ and a width of $0.1-0.4 \mu \mathrm{m}$ (Fig. 1a-d). The evenly distributed porous structures can be clearly observed from the TEM images. On amplifying the images of the shape of one end of the obtained copper tin hydroxide and porous $\mathrm{SnO}_{2}$ hexagonal prism (inset in Fig. 1a and b), a special six-prism shape was observed. Fig. $1 \mathrm{a}$ and $\mathrm{b}$ are the SEM images of the solid hexagonal prisms of copper tin hydroxide and porous hexagonal prisms of $\mathrm{SnO}_{2}$, respectively, and they show a similar morphology. Fig. 1c and d are the TEM images of the porous $\mathrm{SnO}_{2}$ and $\mathrm{Pd} / \mathrm{SnO}_{2}$ hexagonal prisms. Fig. 1f illustrates the TEM image of $\mathrm{Pd}-\mathrm{SnO}_{2} / \mathrm{rGO}$, which indicates that the porous hexagonal prisms of $\mathrm{SnO}_{2}$ maintained the basic morphology after the reduction. Theoretically, $\mathrm{SnO}_{2}$ would turn into stanniferous salts in a strong alkali environment only when the temperature is above $750^{\circ} \mathrm{C}$; thus, its components would not be affected during the entire reaction. The structure of the $\mathrm{SnO}_{2}$ hexagonal prisms was not broken by the airflow caused by the relatively moderate reaction mode of an oil bath, as shown in

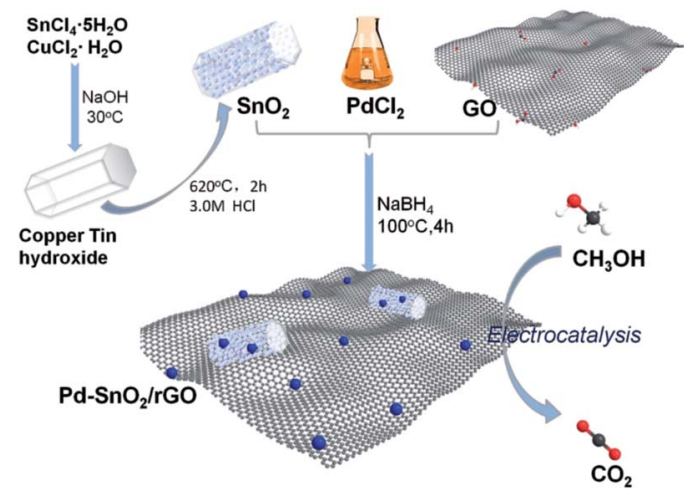

Scheme 1 Schematic for the preparation of porous $\mathrm{SnO}_{2}$ hexagonal prism-attached $\mathrm{Pd} / \mathrm{rGO}$.

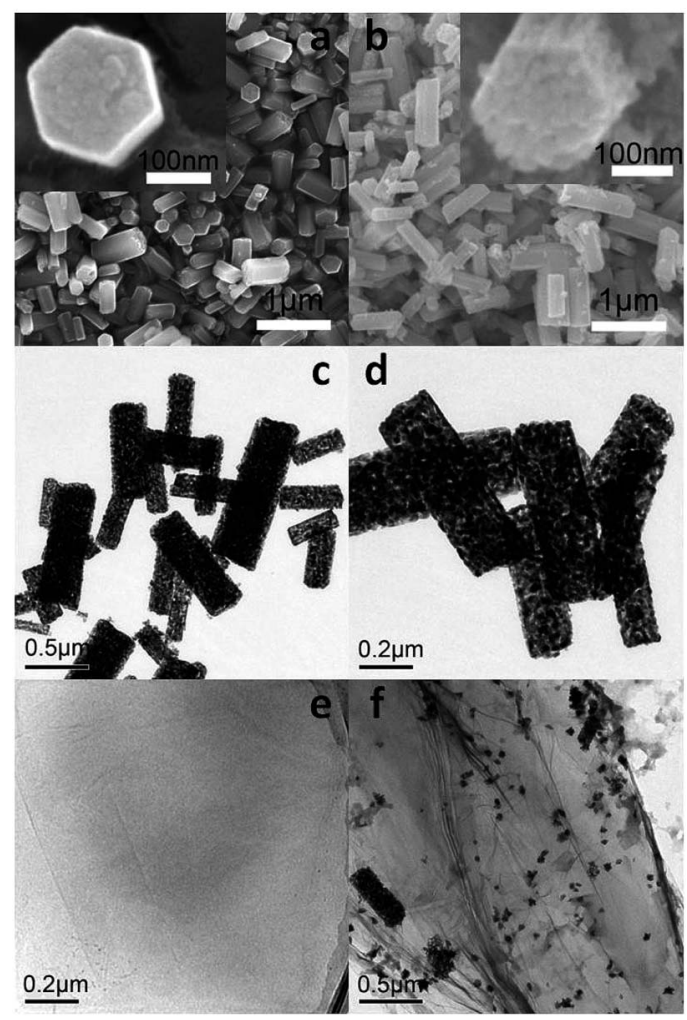

Fig. 1 (a) SEM images of the solid hexagonal prisms of copper tin hydroxide; (b) SEM images of the porous hexagonal prisms of $\mathrm{SnO}_{2}$; (c), and (d) TEM images of the porous $\mathrm{SnO}_{2}$ and $\mathrm{Pd} / \mathrm{SnO}_{2}$ hexagonal prisms. (e) TEM image of $\mathrm{GO}$ and (f) TEM image of $\mathrm{Pd}-\mathrm{SnO}_{2} / \mathrm{rGO}$.

Fig. 1f. Pd nanoparticles on the surface of rGO were uniformly distributed. The TEM image of a few-layered GO is presented in Fig. 1e as a reference.

Fig. 2 shows the XRD patterns for the as-synthesized samples over the $2 \theta$ range of $5-85^{\circ}$. It can be clearly seen from Fig. $2 \mathrm{a}$ that the XRD patterns of the as-prepared and the purchased $\mathrm{SnO}_{2}$ have the same diffraction peaks of $\mathrm{SnO}_{2}$ (JCPDS: 41-1445), which indicates that $\mathrm{SnO}_{2}$ has been successfully synthesized. Pure Pd NPs with face-centered cubic (fcc) crystalline structures show $2 \theta$ values of (111), (200), and (220) that are consistent with the standard values of Pd (JCPDS: 87-0643). The XRD diffraction peaks of the (111), (200), and (220) facets of the fcc crystalline structures can be observed at $2 \theta=39^{\circ}, 45^{\circ}$, and $67^{\circ}$ from Fig. 2b. The plane characteristic peak of Pd (111) was adopted to estimate the average crystallite size $D$ of the Pd NPs following the Scherrer's equation:

$$
D=0.9 \lambda / \beta \cos \theta
$$

In the abovementioned formula, $\lambda(\mathrm{nm})$ is the $\mathrm{X}$-ray wavelength $(\lambda=0.15418 \mathrm{~nm}$ for $\mathrm{Cu} \mathrm{K} \alpha), \beta$ (rad) is the full width at half-maximum (FWHM) of the peak in the diffraction pattern, and $\theta(\mathrm{rad})$ is the Bragg diffraction peak. According to Fig. 2b, the FWHM are $0.830,0.795$, and 0.745 for $\mathrm{Pd} / \mathrm{rGO}, \mathrm{Pd} / \mathrm{SnO}_{2}$, and $\mathrm{Pd}-\mathrm{SnO}_{2} / \mathrm{rGO}$ catalysts, respectively. On calculating using eqn (a), the crystallite sizes of the Pd NPs were found to 10.05, 10.50, 

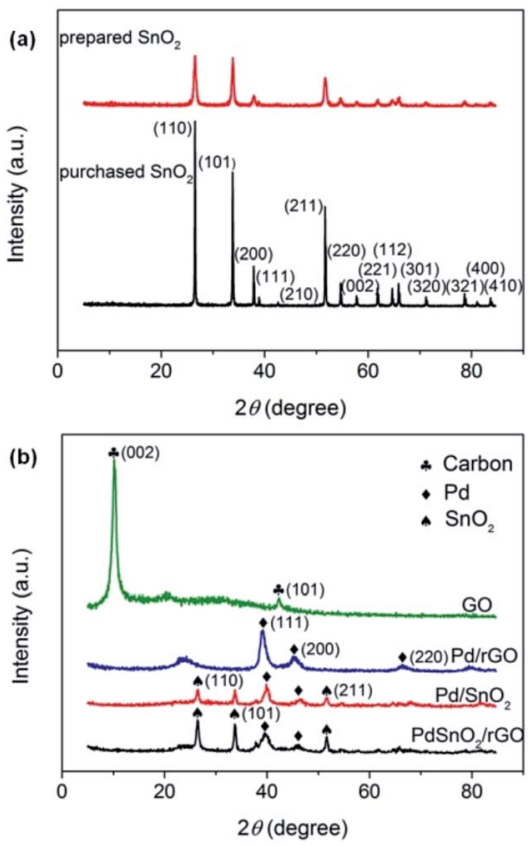

Fig. 2 (a) XRD patterns of the prepared and purchased $\mathrm{SnO}_{2}$ and (b) XRD patterns of the purchased $\mathrm{GO}$ and prepared $\mathrm{Pd} / \mathrm{rGO}, \mathrm{Pd} / \mathrm{SnO}_{2}$, and $\mathrm{Pd}-\mathrm{SnO}_{2} / \mathrm{rGO}$

and $11.20 \mathrm{~nm}$ for the $\mathrm{Pd} / \mathrm{rGO}, \mathrm{Pd} / \mathrm{SnO}_{2}$, and $\mathrm{Pd}-\mathrm{SnO}_{2} / \mathrm{rGO}$ catalysts, respectively. Compared to the peaks of $\mathrm{SnO}_{2}$ shown in Fig. 2a, there are fewer peaks that can be clearly observed. The diffraction characteristic peaks at $2 \theta=26.6^{\circ}, 33.9^{\circ}$, and $51.8^{\circ}$ correspond to the (100), (101), and (211) facets, respectively, of tetragonal $\mathrm{SnO}_{2}$, as shown in Fig. 2b; however, other peaks are weak and cannot even be observed. The faint peaks of $\mathrm{SnO}_{2}$ were hardly observed since the main Pd diffraction peaks and the sharp peaks of $\mathrm{SnO}_{2}$ were comparatively stronger. The crystallinity of $\mathrm{SnO}_{2}$ becomes pronounced in $\mathrm{Pd}-\mathrm{SnO}_{2} / \mathrm{rGO}$ as evidenced by the increased intensity of the diffraction peaks. ${ }^{25}$ Moreover, as shown in the XRD patterns of GO, a sharp peak at $2 \theta=11^{\circ}$ of the $\mathrm{C}(002)$ facets can be observed. The fact that no obvious peaks can be found at the same positions in the patterns of other samples illustrates that GO is indeed partially reduced and $\mathrm{rGO}$ is formed. The XRD pattern of $\mathrm{Pd} / \mathrm{rGO}$ has a wide peak at around $2 \theta=23^{\circ}$, whereas the pattern of $\mathrm{Pd}-\mathrm{SnO}_{2} /$ rGO does not show this peak. This indicates that the reduction degree of GO among $\mathrm{Pd}-\mathrm{SnO}_{2} / \mathrm{rGO}$ was better than that of $\mathrm{Pd} /$ rGO. Moreover, the peak of $\mathrm{SnO}_{2}$ could also hinder the observation of this diffraction peak.

XPS analysis was used for investigating the surface composition and electron configuration of the prepared catalysts. Fig. $3 \mathrm{a}$ and $\mathrm{b}$ reveal the $\mathrm{C} 1 \mathrm{~s}$ regions of the purchased $\mathrm{GO}$ and $\mathrm{Pd}-\mathrm{SnO}_{2} / \mathrm{rGO}$. From the $\mathrm{C} 1 \mathrm{~s}$ spectra of $\mathrm{GO}$ and $\mathrm{Pd}-\mathrm{SnO}_{2} / \mathrm{rGO}$, four components corresponding to $\mathrm{C}-\mathrm{C}, \mathrm{C}-\mathrm{OH}, \mathrm{C}-\mathrm{O}$, and $\mathrm{OH}-$ $\mathrm{C}=\mathrm{O}$ species can be further separated out. On the basis of the correlation of the $\mathrm{C}$ 1s spectrum of graphene oxide (Fig. 3a) and that of the $\mathrm{Pd}-\mathrm{SnO}_{2} / \mathrm{rGO}$ (Fig. 3b), the reduction in the quantity of oxygenated functional groups was observed, also indicating the high reduction of GO via thermal and chemical reactions.
Taken together with the results of XRD and the XPS spectra, it was observed that GO was highly reduced by $\mathrm{NaBH}_{4}$. Spectral peaks of $\mathrm{Pd} 3 \mathrm{~d}$ and $\mathrm{Sn} 3 \mathrm{~d}$ were observed in $\mathrm{Pd}-\mathrm{SnO}_{2} / \mathrm{rGO}$ (Fig. 3c and d), validating the existence of $\mathrm{Pd}$ and $\mathrm{SnO}_{2}$ in the obtained sample. The Pd 3d spectrum, as shown in Fig. 2c, is formed by the Pd $3 d_{3 / 2}$ and Pd $3 d_{5 / 2}$ states, and the two signals can be further deconvoluted into two components of $\mathrm{Pd}^{2+}$ and $\mathrm{Pb}^{0}$, respectively. The percentage of $\mathrm{Pb}^{0}$ is about $77.8 \%$, as measured by the relative peak areas, indicating that after the synthesis process, $\mathrm{Pd}-\mathrm{SnO}_{2} / \mathrm{rGO}$ mainly contain $\mathrm{Pb}^{0}$ with a few oxidation states of palladium from the un-reacted ions. ${ }^{17,26,27} \mathrm{Pd}^{2+}$ was inevitably adsorbed onto the hollow portion of $\mathrm{SnO}_{2}$ owing to the large surface areas of the porous construction and was not totally exposed for the reduction reaction to occur. The Sn $3 \mathrm{~d}$ spectrum, as seen in Fig. $2 \mathrm{~d}$, has two peaks of $S n 3 \mathrm{~d}_{3 / 2}$ at $495.5 \mathrm{eV}$ and $\mathrm{Sn} 3 \mathrm{~d}_{5 / 2}$ at $487.0 \mathrm{eV}$, which is in good agreement with the energy splitting reported for $\mathrm{SnO}_{2}{ }^{28}$ Fig. 2e presents the survey spectra of the porous $\mathrm{SnO}_{2}$ hexagonal prism-attached $\mathrm{Pd} / \mathrm{rGO}$, which reveals that there are no other heteroelements apart from Pd, Sn, C, and O. The O 1s was detected at $530.8 \mathrm{eV}$, where the peak of the oxygen species appeared in $\mathrm{SnO}_{2}$.

The as-synthesized samples were further characterized via their electrochemical properties as a promising catalyst for the methanol oxidation reaction (MOR). The electrocatalytic behaviors of the porous $\mathrm{SnO}_{2}$ hexagonal prism-attached Pd/rGO catalyst were tested; moreover, for comparison, the same tests were carried out for graphene-based Pd (denoted as Pd/rGO), Pd based on porous the $\mathrm{SnO}_{2}$ hexagonal prisms (denoted as $\mathrm{Pd} /$ $\mathrm{SnO}_{2}$ ), and Pd prepared by reducing $5 \mathrm{mM} \mathrm{PdCl}_{2}$ aqueous
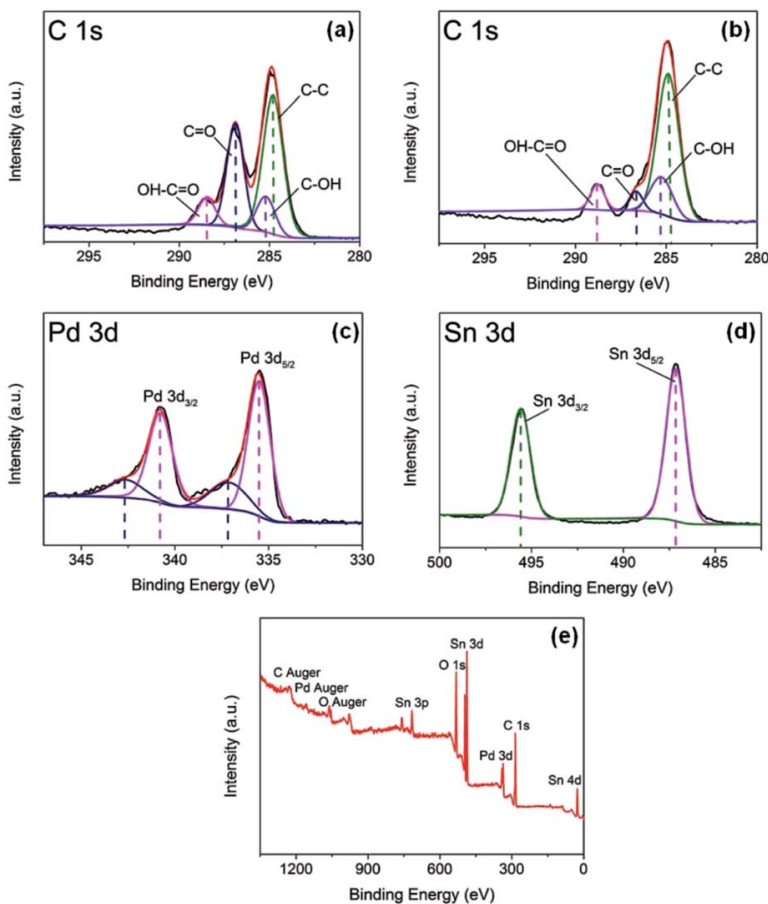

Fig. 3 (a) XPS spectrum for $C$ 1s regions of purchased GO; (b) XPS spectrum for $C 1$ s regions, (c) Pd 3d regions and (d) Sn 3d regions of prepared $\mathrm{Pd}-\mathrm{SnO}_{2} / \mathrm{rGO}$; and (e) XPS survey spectrum for prepared $\mathrm{Pd}-\mathrm{SnO}_{2} / \mathrm{rGO}$. 
solution with $\mathrm{NaBH}_{4}$ to figure out the structural advantages of $\mathrm{Pd}-\mathrm{SnO}_{2} / \mathrm{rGO}$ and the enhancement from porous $\mathrm{SnO}_{2}$ hexagonal prisms and rGO. The catalytic activities of the specimens were acquired through $\mathrm{CV}$ tests in a $\mathrm{N}_{2}$-saturated alkaline solution of $0.5 \mathrm{M} \mathrm{KOH}+1.0 \mathrm{M} \mathrm{CH}_{3} \mathrm{OH}$. The currents of the catalytic activities of different catalysts were standardized, which was realized by the Pd mass, to make a comparison.

As can be distinctly seen in Fig. 4a, highest MA of the porous $\mathrm{SnO}_{2}$ hexagonal prism-attached $\mathrm{Pd} / \mathrm{rGO}$ has a peak current of $1032.8 \mathrm{~mA} \mathrm{mg}_{\mathrm{Pd}}{ }^{-1}$, which is around 1.3, 3.3, and 21.5 times that of $\mathrm{Pd} / \mathrm{SnO}_{2}\left(780.5 \mathrm{~mA} \mathrm{mg}{ }_{\mathrm{Pd}}{ }^{-1}\right)$, Pd/rGO (311.6 $\mathrm{mA} \mathrm{mg}_{\mathrm{Pd}}{ }^{-1}$ ), and Pd (48.1 $\left.\mathrm{mA} \mathrm{mg}_{\mathrm{Pd}}{ }^{-1}\right)$, respectively. After being scattered around the carbon material, in this case rGO, the mass activity of the Pd catalyst dramatically improved. The same enhancement appeared in the anchoring of $\mathrm{Pd}$ on porous $\mathrm{SnO}_{2}$ hexagonal prisms and rGO for increasing amount of transferred charge from the loaded Pd nanoparticals to the rGO funds. Moreover, the lower onset potential of $\mathrm{Pd}-\mathrm{SnO}_{2} / \mathrm{rGO}$ than that of other reference materials (shown in Table 1) shows a substantially improved electrocatalytic activity of the porous $\mathrm{SnO}_{2}$ hexagonal prism-attached Pd/rGO towards methanol oxidation.

As for Pd-based catalysts, the mechanism of MOR under an alkaline condition is as follows: ${ }^{29,30}$

$$
\mathrm{Pd}+\mathrm{CH}_{3} \mathrm{OH} \rightarrow \mathrm{Pd}-\left(\mathrm{CH}_{3} \mathrm{OH}\right)_{\mathrm{ads}}
$$
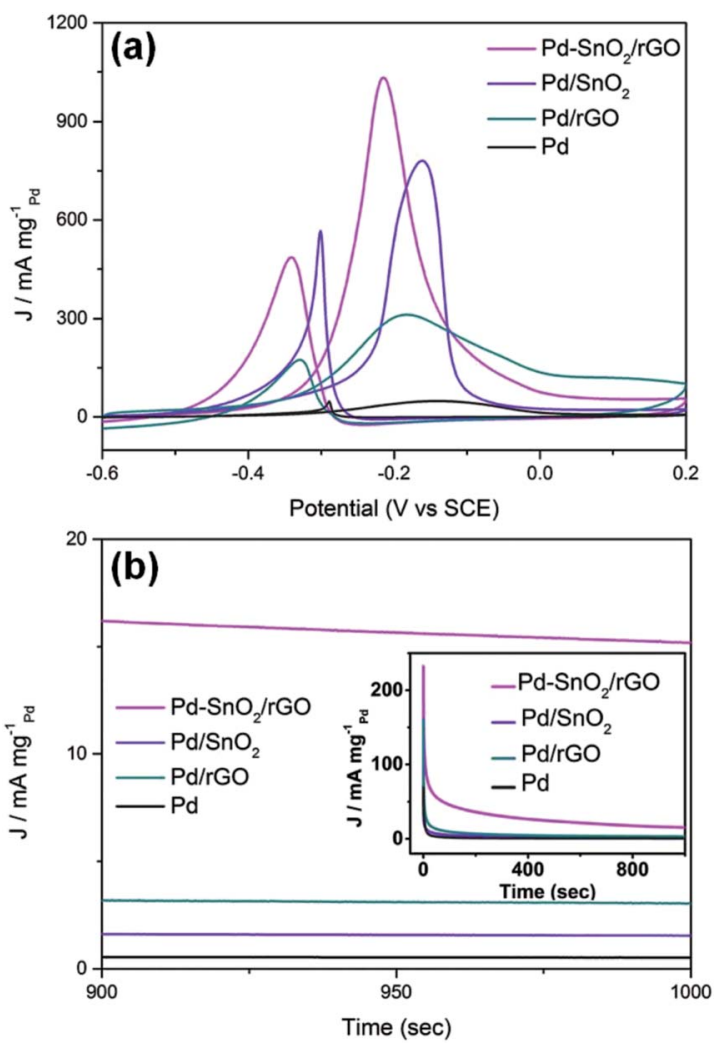

Fig. 4 (a) Cyclic voltammograms and (b) chronoamperometric curve for MOR catalyzed by $\mathrm{Pd}-\mathrm{SnO}_{2} / \mathrm{rGO}, \mathrm{Pd} / \mathrm{SnO}_{2}, \mathrm{Pd} / \mathrm{rGO}$, and $\mathrm{Pd}$ in an alkaline solution of $0.5 \mathrm{M} \mathrm{KOH}$ and $1 \mathrm{M} \mathrm{CH}_{3} \mathrm{OH}$. The $\mathrm{CV}$ s were obtained at a scan rate of $50 \mathrm{mV} \mathrm{s}^{-1}$ and the chronoamperometric curves were obtained at $-0.1 \mathrm{~V}$
Table 1 Catalysts actual loading and electrochemical characteristics of the samples during cyclic voltammograms

\begin{tabular}{lcclc}
\hline & $\begin{array}{l}\text { Pd mass } \\
\text { content } \\
(\mathrm{wt} \%)\end{array}$ & $\begin{array}{l}\text { Peak current } \\
\text { density } \\
\left(\mathrm{mA} \mathrm{mg}_{\mathrm{Pd}}{ }^{-1}\right)\end{array}$ & $\begin{array}{l}E_{\text {onset }} \\
(\mathrm{V} \text { vs. SCE })\end{array}$ & $\begin{array}{l}I_{\mathrm{f}} / I_{\mathrm{b}} \\
\text { ratio }\end{array}$ \\
\hline $\mathrm{Pd}$ & 100.00 & 48.1 & -0.45 & 1.06 \\
$\mathrm{Pd} / \mathrm{rGO}$ & 12.12 & 311.6 & -0.48 & 1.79 \\
$\mathrm{Pd} / \mathrm{SnO}_{2}$ & 49.37 & 780.5 & -0.50 & 1.38 \\
$\mathrm{Pd}-\mathrm{SnO}_{2} / \mathrm{rGO}$ & 12.89 & 1032.8 & -0.52 & 2.13
\end{tabular}

$$
\begin{gathered}
\mathrm{Pd}+\mathrm{OH}^{-} \rightarrow \mathrm{Pd}-(\mathrm{OH})_{\mathrm{ads}}+\mathrm{e}^{-} \\
\mathrm{Pd}-\left(\mathrm{CH}_{3} \mathrm{OH}\right)_{\mathrm{ads}}+\mathrm{OH}^{-} \rightarrow \mathrm{Pd}-\left(\mathrm{CH}_{3} \mathrm{O}\right)_{\mathrm{ads}}+\mathrm{H}_{2} \mathrm{O}+\mathrm{e}^{-} \\
\mathrm{Pd}-\left(\mathrm{CH}_{3} \mathrm{O}\right)_{\mathrm{ads}}+\mathrm{OH}^{-} \rightarrow \mathrm{Pd}-\left(\mathrm{CH}_{2} \mathrm{O}\right)_{\mathrm{ads}}+\mathrm{H}_{2} \mathrm{O}+\mathrm{e}^{-} \\
\mathrm{Pd}-\left(\mathrm{CH}_{2} \mathrm{O}\right)_{\mathrm{ads}}+\mathrm{OH}^{-} \rightarrow \mathrm{Pd}-(\mathrm{CHO})_{\mathrm{ads}}+\mathrm{H}_{2} \mathrm{O}+\mathrm{e}^{-} \\
\mathrm{Pd}-(\mathrm{CHO})_{\mathrm{ads}}+\mathrm{OH}^{-} \rightarrow \mathrm{Pd}-(\mathrm{CO})_{\mathrm{ads}}+\mathrm{H}_{2} \mathrm{O}+\mathrm{e}^{-} \\
\mathrm{Pd}-(\mathrm{CO})_{\mathrm{ads}}+\mathrm{Pd}-(\mathrm{OH})_{\mathrm{ads}} \rightarrow \mathrm{Pd}-(\mathrm{COOH})_{\mathrm{ads}}+\mathrm{Pd} \\
\mathrm{Pd}-(\mathrm{COOH})_{\mathrm{ads}}+\mathrm{OH}^{-} \rightarrow \mathrm{Pd}+\mathrm{CO}_{2}+\mathrm{H}_{2} \mathrm{O}+\mathrm{e}^{-}
\end{gathered}
$$

$\mathrm{CO}$, which is the main poisoning intermediate species of the catalyst, infects the active sites and significantly impedes the access of methanol, and the activity of the Pd-based catalysts thus drops. $\mathrm{CO}$ will be further oxidized to the final product $\mathrm{CO}_{2}$, which corresponds to the backward current density. Therefore, the ratio of the forward and backward oxidation current density $I_{\mathrm{f}} / I_{\mathrm{b}}$ is a vital indicator to measure the endurance of the catalyst to poisoning types that are dominated by CO. ${ }^{31}$ From Fig. 4a, the $I_{\mathrm{f}} / I_{\mathrm{b}}$ value of $\mathrm{Pd}-\mathrm{SnO}_{2} / \mathrm{rGO}$ was detected to be 2.13 , higher than that of $\mathrm{Pd} / \mathrm{rGO}$ (shown in Table 1). The significant increase in $I_{\mathrm{f}} / I_{\mathrm{b}}$ showed that on the surface of $\mathrm{Pd}-\mathrm{SnO}_{2} / \mathrm{rGO}$, methanol was more effectively oxidized and generated less poisoning species than on $\mathrm{Pd} / \mathrm{rGO}$. The reason for this variation is that the addition of $\mathrm{SnO}_{2}$ can promote the rate of methanol electrooxidation, which is closely related to water displacement. The adsorbed hydroxyl groups generated from the water displacement step reacted with the adsorbed $\mathrm{CO}$ and timely removed it, surmounting the COpoisoning obstacle of Pd to a certain extent as follows:

$$
\begin{gathered}
\mathrm{SnO}_{2}+\mathrm{H}_{2} \mathrm{O} \rightarrow \mathrm{SnO}_{2}-(\mathrm{OH})_{\mathrm{ads}}+\mathrm{H}^{+}+\mathrm{e}^{-} \\
\mathrm{Pd}-(\mathrm{CO})_{\mathrm{ads}}+\mathrm{SnO}_{2}-(\mathrm{OH})_{\mathrm{ads}} \rightarrow \mathrm{Pd}+\mathrm{SnO}_{2}+\mathrm{CO}_{2}+\mathrm{H}^{+}+\mathrm{e}^{-}
\end{gathered}
$$

Stability measurements of the catalysts were achieved via chronoamperometry (CA) in a $\mathrm{N}_{2}$-saturated alkaline solution with $0.5 \mathrm{M} \mathrm{KOH}$ and $1.0 \mathrm{M} \mathrm{CH}_{3} \mathrm{OH}$ and conducted at $-0.1 \mathrm{~V} v$ s. SCE for $1000 \mathrm{~s}$. As shown in Fig. 4b, for all the catalysts, the curves show an ultrafast fall-off at the beginning and then gradually reach a state that is approximately steady. The presented initial current was higher for the double layer charge as well as the abundant active sites held by the surface of the 
catalysts. Then, the intermediate products poison the samples and block the surface active sites, leading to a quick decline. ${ }^{32}$ The initial current of the porous $\mathrm{SnO}_{2}$ hexagonal prismattached $\mathrm{Pd} / \mathrm{rGO}$ catalyst was highest as well as steady stage current. Together with the minimal rate of current decay, Pd$\mathrm{SnO}_{2} / \mathrm{rGO}$ definitely had the best poisoning tolerance and catalytic stability. The stronger metal-substrate interaction provides $\mathrm{Pd} / \mathrm{rGO}$ with a higher steady current than that of $\mathrm{Pd} /$ $\mathrm{SnO}_{2}$, and it agrees with the results of the $I_{\mathrm{f}} / I_{\mathrm{b}}$ value calculated by the CVs curves.

To further explore and compare the activities of the electrode materials, the electrochemical active surface areas (ECSAs) were tested. Fig. 5a presents the CVs of the $\mathrm{Pd} / \mathrm{rGO}$ and porous $\mathrm{SnO}_{2}$ hexagonal prism-attached $\mathrm{Pd} / \mathrm{rGO}$ catalysts from the fourth cycle. The CV scanning rate was $50 \mathrm{mV} \mathrm{s}^{-1}$ with a measuring potential ranging from -0.2 to $1 \mathrm{~V}\left(\mathrm{vs}\right.$. SCE) in a solution of $\mathrm{O}_{2}$ removed $0.5 \mathrm{M} \mathrm{H}_{2} \mathrm{SO}_{4}$. A total of four portions can be seen in the sweeping curves corresponding to the four electrochemical redox processes that occur on the surface of three electrodes. The ECSAs of the catalysts based on Pt are normally calculated by obtaining the part of the CV curves corresponding to the coulombic charge for hydrogen desorption integrated in the $\mathrm{CV} \cdot{ }^{33}$ However, the cyclic voltammogram curves of Pd are way too far from those of Pt. Hydrogen is absorbed not only on the surface but strongly enough to be partly absorbed into the lattice of palladium. The $\mathrm{H}_{2}$ absorption started even before the underpotential deposition (UPD) of the absorbed hydrogen atoms and it led to an additional flux of faradaic current. Accordingly, two pathways for the desorption processes of hydrogen to the Pd surface or into the electrolyte from the
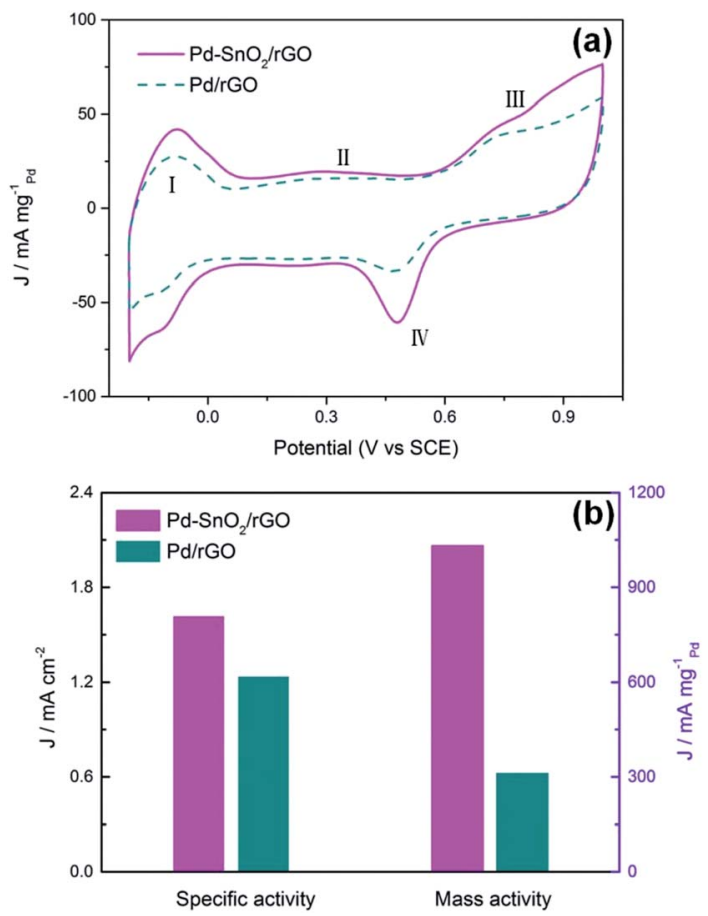

Fig. 5 (a) $\mathrm{CV}$ curves for the $\mathrm{Pd}-\mathrm{SnO}_{2} / \mathrm{rGO}$ and $\mathrm{Pd} / \mathrm{rGO}$ catalystmodified electrodes in $\mathrm{O}_{2}$-removed $0.5 \mathrm{M} \mathrm{H}_{2} \mathrm{SO}_{4}$. (b) The specific activity and mass activity at $0.50 \mathrm{~V}$. lattice of palladium simultaneously proceed in the anodic sweep.

Therefore, the ECSAs were measured by the area of peak IV generated from the reduction of $\mathrm{Pd}(\mathrm{II})$ during backward sweeping. Moreover, peak I can be due to the reaction of hydrogen oxidation, which emerges about between -0.2 and $0 \mathrm{~V}$, and peak III is related to the generation of palladium(II) oxide on the surface of the Pd-based catalysts. ${ }^{6}$ The ECSAs were calculated by integrating the part of the CV curves that presented the reduction charge of the newly formed $\mathrm{Pd}(\mathrm{OH})_{2}$ layer: ${ }^{34}$

$$
\mathrm{ECSA}=\frac{S_{\mathrm{Pd}(\mathrm{OH})_{2}} / V}{0.42 M_{\mathrm{Pd}}}
$$

where $S_{\mathrm{Pd}(\mathrm{OH})_{2}} / V$ is the charge for the reduction of $\mathrm{Pd}(\mathrm{II})$, and $0.42 \mathrm{mC} \mathrm{cm}^{-2}$ is the charge density during the process of generating a thin $\mathrm{Pd}(\mathrm{OH})_{2}$ layer with full coverage, which is the value for a representative single-crystal palladium surface. The $M_{\mathrm{Pd}}$ are obtained by the EDX analysis (shown in Fig. 6). The calculated ECSAs of the catalysts were 25.18 and $63.66 \mathrm{~m}^{2} \mathrm{~g}^{-1}$ for $\mathrm{Pd} / \mathrm{rGO}$ before and after enhancement of the porous $\mathrm{SnO}_{2}$ hexagonal prisms, respectively, in an acid solution. Therefore, our as-prepared $\mathrm{Pd}-\mathrm{SnO}_{2} / \mathrm{rGO}$ catalysts had a more efficient
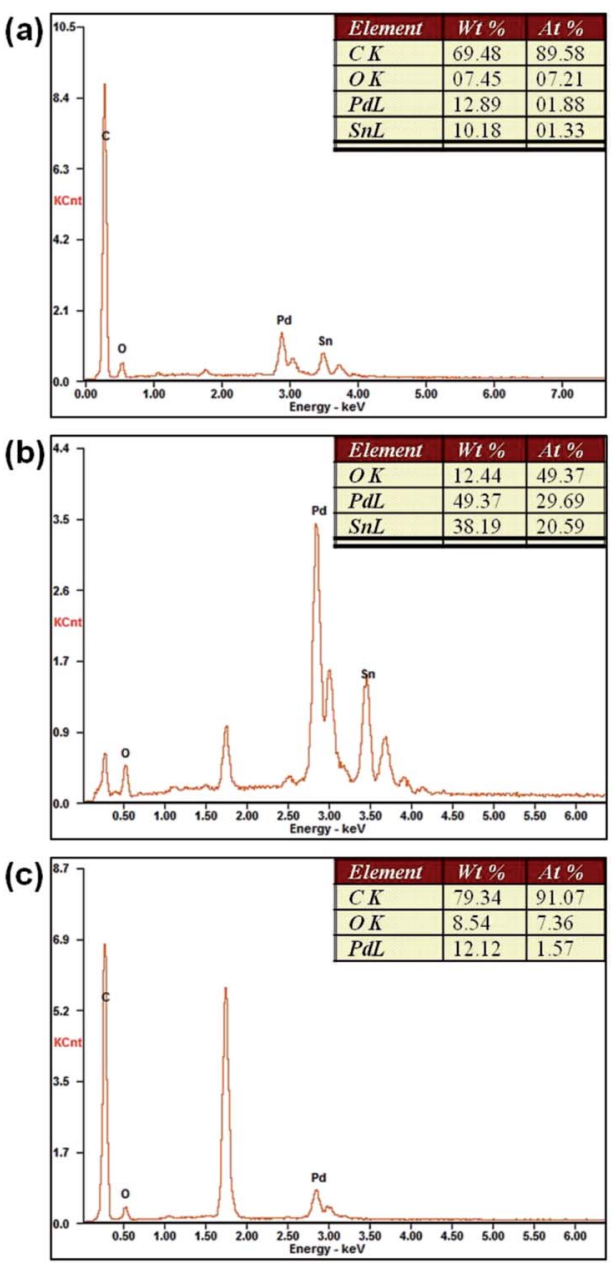

Fig. 6 EDX spectra of (a) $\mathrm{Pd}-\mathrm{SnO}_{2} / \mathrm{rGO}$; (b) $\mathrm{Pd} / \mathrm{SnO}_{2}$; and (c) $\mathrm{Pd} / \mathrm{rGO}$. 
surface structure for MOR. Fig. $5 \mathrm{~b}$ reveals the comparison of the specific activity (SA, $j_{\mathrm{k}}$, area) and mass activity (MA, $j_{\mathrm{k}}$, mass, based on the mass of Pd) of the two catalysts at $0.50 \mathrm{~V}$, where the SA is calculated based on the ECSAs and the MA is calculated from the peak currents of the CVs. For Pd/rGO attached by the porous $\mathrm{SnO}_{2}$ hexagonal prisms, the SA and MA are enhanced 1.31 and 3.3 times those of $\mathrm{Pd} / \mathrm{rGO}$, respectively. The results intuitively show the improvement in the electrocatalytic activity of $\mathrm{Pd}-\mathrm{SnO}_{2} / \mathrm{rGO}$.

\section{Conclusion}

In summary, a simple oil-bath method to prepare porous $\mathrm{SnO}_{2}$ hexagonal prism-attached $\mathrm{Pd} / \mathrm{rGO}$ composite material was described; the composite material was characterized and tested as a catalyst for methanol electrooxidation. We chose $\mathrm{SnO}_{2}$ as a promoter of the Pd-based electrocatalyst to simultaneously cut the cost and accelerate the rate of the pivotal step of MOR. The step, which is water displacement, produces more hydroxyls to combine with the absorbed $\mathrm{CO}$, thus easing the poisoning phenomenon of catalysts of MOR and strengthening the stability. Furthermore, the high surface areas of the porous structure of the $\mathrm{SnO}_{2}$ hexagonal prisms increase the number of active sites. Hollow parts of $\mathrm{SnO}_{2}$ together with the rGO support enable the Pd nanoparticles to be separated instead of being aggregated. The composite's electronic conductivity was also enhanced by the rGO support. Accordingly, in relation to $\mathrm{Pd} /$ $\mathrm{SnO}_{2}, \mathrm{Pd} / \mathrm{rGO}$, and $\mathrm{Pd}, \mathrm{Pd}-\mathrm{SnO}_{2} / \mathrm{rGO}$ has a substantially upgraded electrocatalytic activity and durability for methanol oxidation. This study is a new attempt of using $\mathrm{SnO}_{2}$ with a special morphology for MOR.

\section{Acknowledgements}

This work was financially supported by the National Key R\&D Program of China (Grant 2016YFA0200200) and National Natural Science Foundation of China (Grants 51203045 and 21401049).

\section{Notes and references}

1 X. Cui, Y. Zhu, Z. Hua, J. Feng, Z. Liu, L. Chen and J. Shi, Energy Environ. Sci., 2015, 8, 1261-1266.

2 R. Ganesan and J. S. Lee, Angew. Chem., Int. Ed. Engl., 2005, 44, 6557-6560.

3 Y. G. Guo, J. S. Hu, H. M. Zhang, H. P. Liang, L. J. Wan and C. L. Bai, Adv. Mater., 2005, 17, 746-750.

4 H. Huang, J. Zhu, D. Li, C. Shen, M. Li, X. Zhang, Q. Jiang, J. Zhang and Y. Wu, J. Mater. Chem. A, 2017, 5, 4560-4567.

5 C. Bianchini and P. K. Shen, Chem. Rev., 2009, 109, 41834206.

6 Y. Ren, S. Zhang and H. Li, Int. J. Hydrogen Energy, 2014, 39, 288-296.

7 K. Mandal, D. Bhattacharjee, P. S. Roy, S. K. Bhattacharya and S. Dasgupta, Appl. Catal., A, 2015, 492, 100-106.

8 Y. Xiong, W. Ye, W. Chen, Y. Wu, Q. Xu, Y. Yan, H. Zhang, J. Wu and D. Yang, RSC Adv., 2017, 7, 5800-5806.
9 R. S. Amin, R. M. A. Hameed and K. M. El-Khatib, Appl. Catal., B, 2014, 148-149, 557-567.

10 Z. Li, L. Ye, Y. Wang, S. Xu, F. Lei and S. Lin, RSC Adv., 2016, 6, 79533-79541.

11 S. Roy Chowdhury, S. Ghosh and S. K. Bhattachrya, Electrochim. Acta, 2017, 225, 310-321.

12 Y. Song, X. Zhang, S. Yang, X. Wei and Z. Sun, Fuel, 2016, 181, 269-276.

13 Y. Luo, Y. Xiao, G. Cai, Y. Zheng and K. Wei, Appl. Catal., B, 2013, 136, 317-324.

14 B. L. Caetano, F. Meneau, C. V. Santilli, S. H. Pulcinelli, M. Magnani and V. Briois, Chem. Mater., 2014, 26, 6777-6785.

15 D. Sebastian, A. Stassi, S. Siracusano, C. L. Vecchio, A. S. Arico and V. Baglio, J. Electrochem. Soc., 2015, 162, F713-F717.

16 Y. Y. Tong, C. D. Gu, J. L. Zhang, M. L. Huang, H. Tang, X. L. Wang and J. P. Tu, J. Mater. Chem. A, 2015, 3, 4669-4678.

17 L. Nan, Z. Fan, W. Yue, Q. Dong, L. Zhu, L. Yang and L. Fan, J. Mater. Chem. A, 2016, 4, 8898-8904.

18 M. Liu, R. Zhang and W. Chen, Chem. Rev., 2014, 114, 51175160.

19 D. Chen, Y. Zhao, X. Peng, X. Wang, W. Hu, C. Jing, S. Tian and J. Tian, Electrochim. Acta, 2015, 177, 86-92.

20 M. A. Shenashen, D. Hassen, S. A. El-Safty, M. M. Selim, N. Akhtar, A. Chatterjee and A. Elmarakbi, Adv. Mater. Interfaces, 2016, 3, 1600743.

21 M. Wang, Z. Ma, R. Li, B. Tang, X.-Q. Bao, Z. Zhang and X. Wang, Electrochim. Acta, 2017, 227, 330-344.

22 F. Colmati, E. Antolini and E. R. Gonzalez, Electrochim. Acta, 2005, 50, 5496-5503.

23 Y. J. K. C. Chen, Z. Y. Huo, Z. W. Zhu, W. Y. Huang, H. L. Xin, D. G. L. J. D. Synder, J. A. Herron, M. Mavrikakis, M. F. Chi, Y. D. L. K. L. More, N. M. Markovic, G. A. Somorjai, P. D. Yang and a. V. R. Stamenkovic, Science, 2014, 343, 1339.

24 J. Huang, X. Xu, C. Gu, S. Yao, Y. Sun and J. Liu, CrystEngComm, 2012, 14, 3283.

25 Z. Wang, D. Luan, F. Y. Boey and X. W. Lou, J. Am. Chem. Soc., 2011, 133, 4738-4741.

26 D.-X. Yu, A.-J. Wang, L.-L. He, J. Yuan, L. Wu, J.-R. Chen and J.-J. Feng, Electrochim. Acta, 2016, 213, 565-573.

27 S. Guo, S. Zhang, X. Sun and S. Sun, J. Am. Chem. Soc., 2011, 133, 15354-15357.

28 H. Song, L. Zhang, C. He, Y. Qu, Y. Tian and Y. Lv, J. Mater. Chem., 2011, 21, 5972.

29 R. S. Amin, K. M. El-Khatib, S. Siracusano, V. Baglio, A. Stassi and A. S. Arico, Int. J. Hydrogen Energy, 2014, 39, 9782-9790.

30 G. Hu, F. Nitze, H. R. Barzegar, T. Sharifi, A. Mikołajczuk, C.-W. Tai, A. Borodzinski and T. Wågberg, J. Power Sources, 2012, 209, 236-242.

31 T. Wang, W. Cui, M. Peng, S. Ouyang and S. Wang, J. Mater. Chem. A, 2016, 4, 8584-8589.

32 Z. Bo, D. Hu, J. Kong, J. Yan and K. Cen, J. Power Sources, 2015, 273, 530-537.

33 S. Lu, K. Eid, D. Ge, J. Guo, L. Wang, H. Wang and H. Gu, Nanoscale, 2017, 9, 1033-1039.

34 L. Z. L. Xiao, Y. Liu, J. T. Lu and H. D. Abruna, J. Am. Chem. Soc., 2009, 131, 602-608. 